\title{
College English Teaching Mode in MOOC Era
}

\author{
Ying Wei \\ Foreign Language School \\ Huanghe Science and Technology University \\ Zhengzhou, China
}

\begin{abstract}
With the process of China's higher education development and large-scale network online resources in the world, MOOC courses have become the beneficial supplement of higher education resource, not only bringing changes for the teaching organization form and teaching methods, but also students have become more and more flexible in selecting courses. The paper combines MOOC and college English teaching in class, in order to analyze opportunities and challenges that traditional college English teaching encounters with, and then construct the classroom teaching model under the background of large-scale network open courses. What's more, through the discussion of a flipped-class case study, the author attempts to stimulate the establishment of interactive information sharing platform, transform teacher's role and promote the integration of the traditional college English classroom and Internet courses.
\end{abstract}

Keywords-MOOC; flipped-class; college English teaching; reform of English teaching in class

\section{OPPORTUNITIES AND CHALLENGES IN MOOC ERA}

With the MOOC development, traditional college English teaching encounters with a lot of opportunities. On one hand, the spread and application of MOOC facilitates the integration of high-qualified education resources, the introduction of great network courses of English teaching, the improvement of teaching levels and the innovation of English teaching theory and practice. While on the other hand, students obtain high-qualified courses in large quantity through the internet, which will greatly reduce the students' interest on traditional class teaching. Faced with the challenge that MOOC brings, teachers, with the assistance of network courses, are expected to update their knowledge storage and expand innovative English class-teaching mode, to become the leaders of flipped-class English teaching in MOOC era.

\section{Elements of College English Teaching Mode IN MOOC ERA}

Through exploring the relationship among elements in English teaching system, it is found that college English teaching mode in MOOC era is constructed by expanding a frame structure of "one principal, two aspects, three upholders and four basic points". "One principal" means building a curriculum system combined with online courses. "Two aspects" is that the curriculum system should contain English language and foreign cultural characteristics, blend western cultural characteristics and construct a harmonious cultural atmosphere to build a good foundation for improving students' English level. "Three upholders" includes curriculum, teachers' qualification and teaching methods, which are conducted through the combination of MOOC standards and the quality requirement of English teaching. It has higher requirement for English teacher in academic degree, professional title, scientific research ability, teaching ability and cooperation. The students' English is promoted by combining learning, teaching and multimedia material. "Four basic points" is teaching idea, teaching method, teaching content and teaching evaluation.

A new teaching mode called "learning outside class and internalization in class" has been rising under the background of MOOC. The students do not need spend much time to receive explanation of concepts and operating method form teachers. This kind of "flipped class" has been accepted by reversing traditional teaching method. Students learn outside class by watching teaching videos with the help of information technology, while students in the class participate knowledge-related discussion, exploration and interaction.

\section{MODEL DESIGN OF FLIPPED ClASS ENGLISH TEACHING}

Flipped class is characterized by information, cooperation and interaction. Teaching model is composed of before-class learning and after-class learning. As two effective levers to create learning environment, information technology and learning activities guarantee the constructions and creations of cooperative and personalized learning environment.

\section{A. Before-class Preparation}

Teachers are required to grasp the definite teaching aims and language points, then set up teaching schedule and learning tasks. Based on personal interpretation of related knowledge and application circumstance, teachers select resources which are consistent with teaching contents as elements of teaching videos, classify and reprocess existing teaching resources to provide video copied and text material for students. In that case, it is feasible for students to review and reflect on teaching videos as they like.

\section{B. In-class Organization}

Time in class should be assigned for students to practice language. Students have taken notes on difficult points 
during self-study process by watching teaching videos before class. Then they come to the stage of learning in class. Now, the students come to class with self-confidence to understand key knowledge point, curiosity of practicing language culture and confusion to some difficult problems. Through experiencing language atmosphere and discussing between teacher and students, some difficult problems in English learning can be solved and personal knowledge can be internalized.

\section{Cooperative-Group Learning}

Students are divided into several leaderless group randomly according to class size or degree of task difficulty. Every group should make a study plan according to the finishing time of a task. The crew should carry out his duty in the project plan. When having many groups, the crew will put their heads together to deal with difficulties and give their own opinion. Due to different plans, compositions, paces and problems in the reading process, teachers' assistants are needed.

\section{Class Discussion}

For difficult problems, teachers and assistants will participate into discussion to guide student to solve problems. In flipped-class, students are led to get used to discussing first and then getting help form teacher when difficulty occurs. This learning style can't guarantee teaching pace completely in accordance with pre-set teaching schedule. Teachers should be familiar with teaching process and predict possible problems so as to deal with emergent situation in teaching process.

\section{E. End Stage of Teaching}

Teachers should summarize possible pitfalls in English teaching model, and look up related sources to further study them in detail and update course ware timely to widen the depth and breadth of the teaching materials.

\section{A CASE STUDY OF FLIPPED-CLASS ENGLISH TEACHING}

The author takes "New Horizon English Book 3" as an example, and designs a flipped-class teaching model which is based on MOOC resources. Every unit is divided into six modules in teaching: topic-related words, text theme, structure analysis, culture interpretation, writing guide, free ask and question. On basis of course contents, teachers are required to search related MOOC videos, well-prepare PPT, audios and other electronic network resources. Students selfstudy most contents of each module after class, a practice learned-knowledge by discussing in groups and giving presentations in class. Knowledge-internalization is maximized through the design of class activities. The author leads students to register in a MOOC course "English Writing 1" made by Professor Denise Comer on Coursera MOOC Platform. By means of watching teaching videos, students can better understand the writing process. What's more, their compositions are of high quality, writing skills as well as practical writing ability are greatly improved, which are the results of their personal writing practice, class discussion, the feedback and evaluation from other students and teachers. As for teachers, they timely reflect on the problems which arose in students' learning process, sum up experience and lessons, with the aim of providing inference for lesson plans and class organization.

The practice has proved that flipped-class English teaching, which is based on MOOC resources and mobile learning technology, has enriched the learning contents for students, made the teacher- student's interaction and studentstudent interaction more timely and effective. In that situation, forced-feeding teaching mode has transformed into a heuristic and exploratory teaching mode, fully demonstrating students' predominant role in learning process, the ability improvement of personalized learning and independent learning.

\section{CONCLUSION}

There are some defects in traditional English teaching. This paper raises a new way to build college English teaching and learning model by using the newest teaching concepts and model, modern mobile internet technology and MOOC. It is flexible to use MOOC resource, such as referring to high quality MOOC resource of online MOOC platform, creating your own MOOC resource according to students' major or English and encouraging students to recommend or make their personalized MOOC resource. The development of school information technology also provides technical support to carry out reverse course. It is possible to carry out reverse course based on MOOC resource and mobile learning by widespread using mobile communication equipment. Under teacher's correct guidance and supervision, It provides reference to solve low efficient long-standing problems in college English teaching and make students Interacting and participating in reverse course to improve and push college English teaching. So as to promote teaching, It is also a long exploration and practice process to create high quality MOOC course and integrate current MOOC resource. But the practice of college English reverse course based on MOOC resource and mobile learning is an exploration of teaching reform. I can activate teacher to find more creative, attractive, humanized and effective learning model.

\section{REFERENCES}

[1] Gibert Grimes Weaver, Louis Cenci. Applied Teaching Techniques[M]. Cornell University. Pitman Pub. Corp, 1960.

[2] Gao Di The Core Idea of MOOC, Practice Reflection and Culture Security, Journal of Northeast Normal University (PHILOSOPHY AND SOCIAL SCIENCES EDITION), 2014(5):178-186.

[3] Guo Yingiian. The Current Situation, Dilemma and Future of MOOC in the World [J]. University Education Management, 2014 (7): 42-48.

[4] Stephen. Related Theories of MOOC (C MOOC) and the Traditional MOOC (x MOOC) [E B/OL]. [2014- 0 4-16]. http://www.downes.ca/. 